\title{
Renal pathology associated with kidney stones in two buffaloes
}

\author{
Sidhartha Deshmukh*, Harmanjit Singh Banga ${ }^{\dagger}$, Nittin Dev Singh ${ }^{\dagger}$ and Rajinder Singh Brar $^{\dagger}$
}

*Correspondence: sid0159@yahoo.com

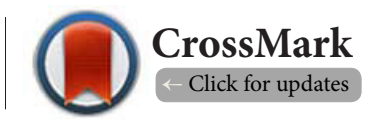

'These authors contributed equally to this work.

Department of Veterinary Pathology, College of Veterinary Science, Guru Angad Dev Veterinary and Animal Science University, Ludhiana-141004, Punjab, India.

\begin{abstract}
Background: Reports on kidney stone incidences in large animal is not uncommon and that too in buffaloes. Despite, their repeated recording during post mortem examination, detailed elaboration of their effect on renal system including anatomical and functional changes were not described sufficiently. It is believed that nutritional alteration(s) in feeding regimen of large animals play significant reason(s) to their formation. Besides this, the current medication practices being followed in Indian situation that includes indiscriminate prescription of non steroid anti-inflammatory drugs (NSAIDS) for pain management in large animal as well as in human subject is highly alarming due to potential stone formation and is a matter of public health concern with respects to its imminent detrimental effect on renal system structure and functioning and thus disastrous impact on animal and human health. This study could acts an eye opener for all of us. Possible and considerable degree of utilization of accumulated updates on this subject delivered a valuable discussion to this case article.

Findings: Spontaneous presence of renal stones in kidney was a prominent observation. On histopathological examination, the study revealed remarkable changes characterized by interstitial fibrosis near renal calices, capillaries extravasation(s) and mild angiogenesis in first case, while in second case, marked chronic renal fibroplasias/fibrosis and formation of indented proximal convoluted tubules and cystic dilatation of other renal tubules. Most of renal interstitium apparently showed marked dense collagenous matrix resembling to indistinct bony matrix, which was clearly discernible with Masson's Trichome staining.

Conclusion: This study elucidated vivid renal pathology due to renal-lithiasis in buffaloes which is almost negligible and scanty. This case reports also endeavoured to ascertain probable causes of renal alterations seen in the present cases through thoughtful screening and sincere review of updates. It is also construed from this study that the relevant observation noted could be utilized to study the human renal complications and effective management to such situation could be evolved through further research on veterinary patients.
\end{abstract}

Keywords: Buffalo kidney, renal pathology, nephrolithiasis, renal fibrosis

\section{Introduction}

Kidney stones in ruminants are mainly incriminated to nutritional alteration(s) in their feeding regimen, despite various reasons attributed to their formation. Their occurrence is not uncommon and reportedly evident following high concentrate feeding cotton seed meal and rice straw with preponderus phosphorus and magnesium contents with a tendency to keep low calcium to phosphorus ratio, i.e., 1:1 in feed [1-4], which has been linked to formation of struvite crystals in kidney. Males are comparatively more vulnerable owing to their inherent anatomical difference(s) $[5,6]$. In addition to this, mineral content of water, in concert with dietary imbalances also persuade towards formation of renal liths in animal(s) [7]. Incidentally, we report here, two different cases of spontaneous occurrence of renal lithiasis in female buffaloes, noticed during post-mortem examination(s). The little documentation on kidney pathology, 
due to renal-liths in buffalo necessitated a detailed study to carry forward on pathological aspects to divulge any ensuing major changes noted in kidney(s) and other parts of renal system as and when compared to other species.

\section{Case presentation \\ Case I}

The first case observed was of a female buffalo, aged 6 years, admitted to Teaching Veterinary Clinical Complex, Guru Angad Dev Veterinary and Animal Science University (GADVASU), Ludhiana with a history of fever, acute bloat, anorexia, and recumbency besides being suspected for a dog bite. Clinically, the animal exhibited congested mucus membrane with ruminal $\mathrm{pH}$ recorded at 6 . The animal was treated with Tetracycline $\left(\right.$ Terramycin ${ }^{\circledR}$ ) and Diclofenac (Non Steroid anti-inflammatory drug) by a local veterinarian before being brought to GADVASU clinical complex. During course of therapy at GADVSAU, the animal was treated with injection Gentamicin and ACVet ${ }^{\circledR}$ beside bolus Rumental ${ }^{\circledR}$ and Powder Impedon $^{\circledR}$. The animal did not responded to the treatment and died and was sent for necropsy. At necropsy; the animal didn't reveal any superficial lesion of a dog bite. The cue of presence of putative kidney stones was not obvious in this case. The kidneys when cut produced gritty sound, exhibited small broken yellowish brown stones with varied shapes near the pelvis (Figure 1) particularly, limited to the neck of pelvis. On gross examination, marked areas of congestion and haemorrhages were noticed in both the renal pelvis. The urinary bladder was found to be ruptured with presence of hemorrhagic streaks on the mucosal surface, but no stones or any other material was seen. Notably, at one place, marked sloughing of ruminal mucosa with presence of big area of haemorrhagic blotch, beneath the mucosal lining was observed. The abomasal mucosa revealed marked haemorrhages and severe haemorrhagic enteritis as observed throughout the length of intestine. The epicardium revealed presence of

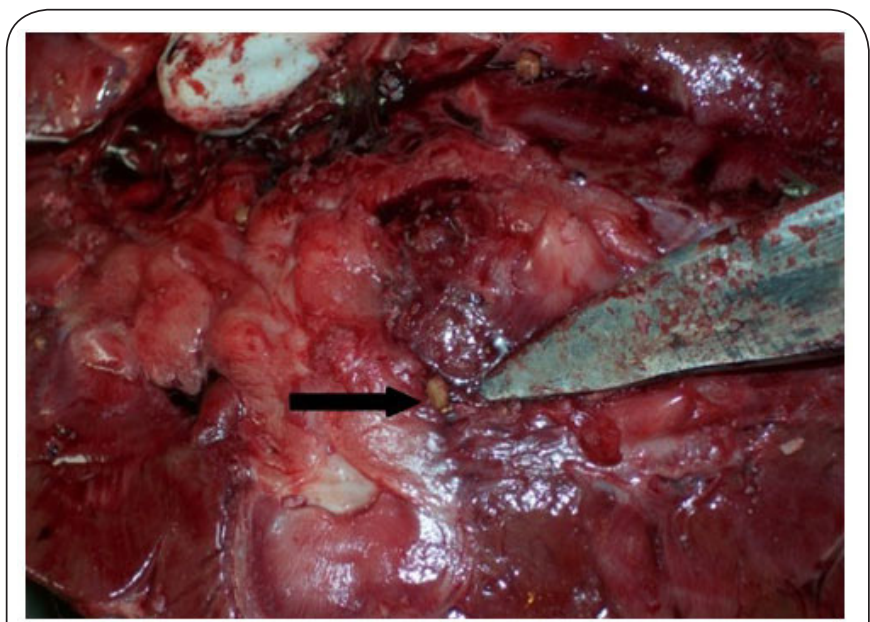

Figure 1. Kidney, (Case I) showing small broken yellow brown stones (Arrow) at calyx and also in other parts of the kidney. scattered parallel and linear petechial haemorrhages, while endocardium revealed characteristic linear haemorrhagic streaks. The lungs appeared emphysematous at patches with coagulated blood in major pulmonary blood vessels.

\section{Case II}

The second case was observed in 9 year old pregnant buffalo presented with a clinical anamnesis of chronic fever gradually stoop to sub normal temperature, forceful micturation and recumbency, for at least one week, till death. During necropsy, the kidney on both sides revealed large number of cylindrical shaped and broken yellowish brown stones in the renal calices which extended up to renal pelvis exhibiting areas of congestion and haemorrhages. Due to larger area of bovine renal hilus containing ramified network of minor as well as major calices, widely, scattered presence of variably large sized stones were noticed predominantly in most of the zone of calices. Notably, no significant gross pathology was observed in urinary bladder. Other significant lesions noted were round heart with evidence of petechial to echymotic haemorrhages in the sub-epicardium. The lungs appeared emphysematous at patches and liver was enlarged with characteristics embossed rib impression on its surface besides thickening of its capsule. There was spleenomegaly with petechial haemorrhage(s) throughout its surface. The abomasum revealed wide and extensive areas of haemorrhages throughout its mucosa, simulating the red glistening smooth surface of cherry. The various haematological parameters associated with the cases are presented in Table 1.

Table 1. Various haematological parameters associated with the two case of renal-lithiasis in buffaloes.

\begin{tabular}{llll}
\hline Haematological parameters & Case I & Case II & Normal range \\
\hline Haemoglobin $(\mathrm{g} \%)$ & 14.2 & 11.0 & $9-15$ \\
Total leukocyte count $\left(10^{3} / \mu \mathrm{l}\right)$ & 10.8 & 9.4 & $6-13$ \\
Neutrophil (\%) & 78 & 73 & $16-56$ \\
Lymphocyte (\%) & 22 & 22 & $44-84$ \\
Monocyte (\%) & -- & 02 & $2-8$ \\
Eosinophil (\%) & -- & 03 & $2-14$ \\
Basophil (\%) & -- & -- & Rare \\
\hline
\end{tabular}

However, infectious aetiology behind the genesis of renal stone formation in both the cases could not be ruled out. The requisite organ sample(s) from both cases were collected, fixed in $10 \%$ neutral buffered formalin and embedded in paraffin wax. Sections at 4-6 $\mu \mathrm{m}$ thick were stained with haematoxylin and eosin (H\&E) and further special staining with Masson's Trichome stain was performed to know the extent of lithiasis induced in kidneys [8].

\section{Results and discussion}

The studies on pathology of nephrolithiasis in buffalo are 
almost negligible. This paper intent to highlight some prominent changes having bearing on structural and functional unit of kidney owing to stone formation or other ancillary processes which can be extrapolated for other bovine as well as veterinary patients. It is noteworthy to include the fact, that adult bovine kidney(s) is also considered as one of the model for certain urologic procedures to study the human renal complications, with some special considerations [9], besides pig kidneys which frequently served as a model of research and training in nephrolithotomy $[10,11]$. The present study on natural occurrence of kidney stones in buffalo endeavoured to elucidate the probable cascading development of lesions to understand the in-depth matrix and probable aetiology. The study includes two cases from adult female buffaloes, whereby one died without exhibiting obvious symptom and other innuendo towards involvement of renal system, during life i.e., before death. The histological examination of the kidney from case I, revealed the presence of widespread proximal tubular necrosis with focal presence of undisturbed distal convoluted tubules in the cortex. The cuboidal epithelium in most of the proximal convoluted tubules (PCT) appeared to have undergone parenchymatous degeneration. Their nuclei had either disappeared or were left as ghost cell, which stained feebly. At many places, epithelial cells appeared loosened from each other and from the basement membrane, simply restricted by strict and intact peritubular membrane, fashioned around a central lumen. In some of the tubules, individualization of cuboidal epithelial cells was noted, which marked the beginning of necrobiotic changes within themselves. Those cells revealed highly eosinophilic cytoplasm with pyknotic nuclei. Some of the glomeruli in cortex showed increased mesangial matrix with resultant thinning of Bowman's spaces. Interestingly, irregular mild desquamation of parietal layer of few Bowman's capsules was evident besides congested glomerular capillaries in few enlarged juxtramedullary glomeruli.

Currently, the newer concept of therapeutics in bloat includes use of non steroidal anti-inflammatory drugs (NSAID) along with antibiotics and mineral oil supplementation. The NSAIDs is constitutively a preferred regimen for pain management in clinical practice(s). The pain arises due to over distension of ruminal wall, making the animal bilious and excited. The usages of non steroidal formulations have an inherent potential to induce papillary necrosis and nephrotic syndrome [12], and its indiscriminate usage is rampant in veterinary practice leading to a common outcome. The NSAIDs generally cause reduce blood flow to kidney which engender hypoxic affects to induce serious changes like acute tubular changes [13] to proximal convoluted tubules. The epithelium of proximal convoluted tubules is sensitive to hypoxia and undergoes immediate degenerative changes as result of increase in cytosolic calcium $\left(\mathrm{Ca}^{2+}\right)$ [14], comparatively to distal tubular epithelial cells [15] and collecting tubular epithelial cells. The peritubular capillaries in the renal medullary zone revealed marked distension of vessels, engorged with erythrocytes (Figure 2). Occasional numbers of medullary distal convoluted tubules were found to be plugged with distinct eosinophilic material. Necrosis was not significant, but few tubules were involved. The diffuse areas of fibrosis were mainly observed near renal calices which were infiltrated with mononuclear cells and few polymorphonuclear cells. The distal convoluted tubules (DCT) and peritubular capillaries near to renal calyx were largely affected by diffuse interstitial fibrosis, as most of them were sequestered by the proliferative connective tissues i.e., fibrosis and nearby capillaries showed extravasations at many places. The fibrotic areas is characterized by laying down of interstitial matrix with resultant widening of interstitial area, which may contribute to initial proliferation of interstitial fibroblast. The appearance of fibrosis seems to have arisen following loss of apical basal polarity maintained by epithelial cells to their basement membrane following suspected stimulations by NSAID induced toxicity [16]. The deeper connective tissue portion of renal papillae showed mononuclear cell infiltrations and thickening of few existing blood vessels along with fewer angiogenesis (Figure 3 ). In this case, histological appreciation of the matrix behind reason of stone formation is unclear and insidious fibrosis has been accentuated. Unfortunately, no blood biochemical work report is available with this case to equate the condition. The gross lesions in rumen and abomasum from this case also clearly indicate towards the possible disruption of prostaglandin synthesis by the gastrointestinal cells owing to arrest of Cyclo-oxygenase (COX) enzymes, thus leading to gastrointestinal injury [17]. The important microscopic pathology in case II, includes marked thickening of interstitium, owing to proliferation by collagenous tissue, prominent indentation of large proximal convoluted tubules (PCT) and thickening of basement membrane of every Bowman's capsules, either in cortex or in cortico-meduallry junction. Comparatively, the

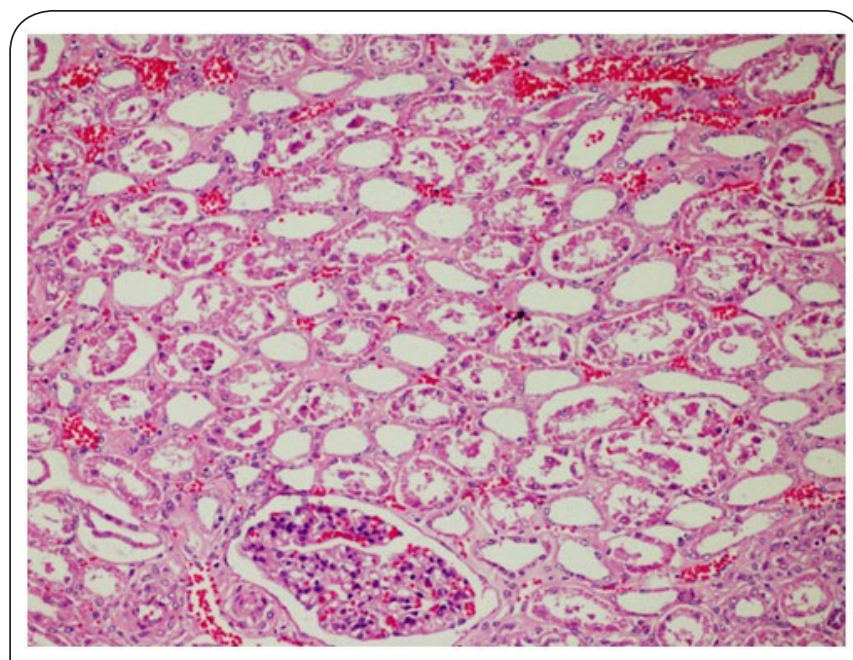

Figure 2. Kidney, (Case I), Marked congestion of peritubular capillaries in medullary zone. HE Bar $=100 \mu \mathrm{m}$. 
extent of interstitial fibrosis was very extensive in this case, which included disappearance of glomeruli, renal tubules and collecting ducts out of place in both cortex and medullary zones, up to renal papillae. The indentation noticed, was due to unkempt proliferation of fibrous connective tissue, which resultantly created fission of large PCTs at some places (Figure 4). The renal tubules were found degenerated with thickened basement membrane at numerous places. Even some of the renal tubules exhibited marked thinning of cuboidal lining, which resulted in the formation of cystic tubules (Figure 5). Such tubules were apparently laden with eosinophilic proteineous secretions. There was marked enlargement of glomeruli with widening of Bowman's space which defines putting out of action of nephron, the functional unit of kidney in the case. At some places, the renal corpuscles (glomerulus and Bowman's space)

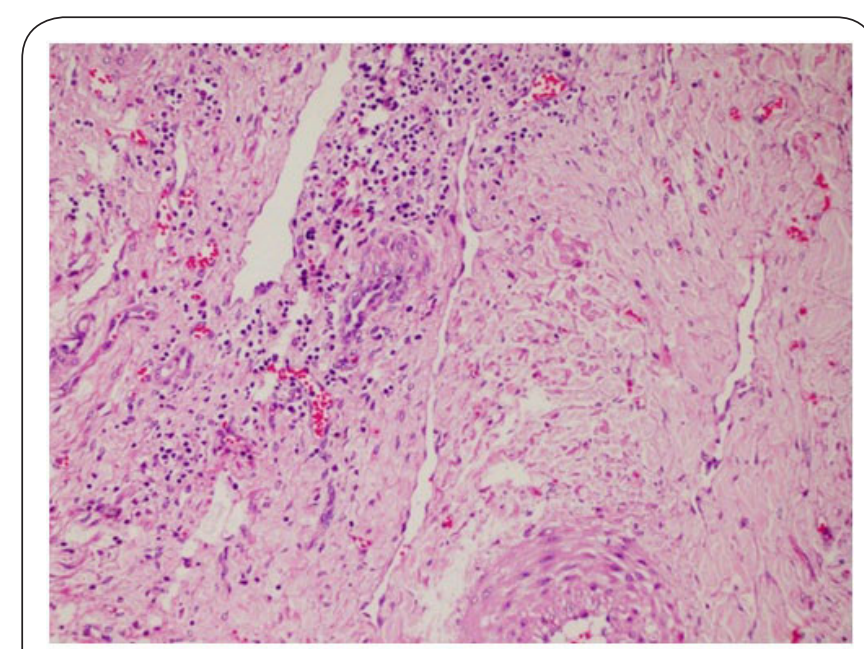

Figure 3. Kidney, (Case I), Focally extensive mononuclear cell infiltration and evidence of thickened blood vessels in renal calyx. HE Bar $=100 \mu \mathrm{m}$.

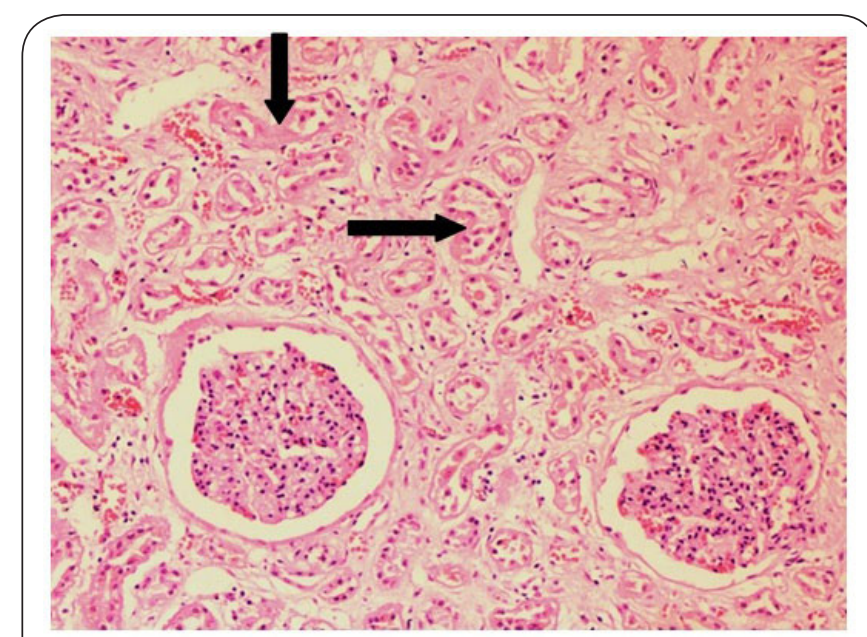

Figure 4. Kidney, (Case II), showing indented proximal convoluted tubules (Arrows) due to marked proliferation of fibrous connective tissue. HE Bar $=100 \mu \mathrm{m}$. appeared occluded with adhesions between glomerulus and Bowman's capsule. The changes like mesangial cell hyperplasia and congestion of glomerular tufts allude to dysfunctioning of normal urinary filtration process and passive hyperaemia to this case. The inflammatory cell infiltration(s) predominantly populated with mononuclear cell and few neutrophils. The distal convoluted tubules (DCT), peritubular capillaries and some inter-tubular arteries appeared squeezed and sandwiched between exasperated connective tissues, resultantly produced zone of haemorrhages and small (atrophied) misshapen tubules and ducts. Special staining with Masson's Trichome revealed greenish fibrous matrix of interstitium which simulated very close to indistinct bony matrix (Figure 6). Apparently this case belongs to chronic renal fibrosis, associated with dietary levels of minerals or carbohydrate contents

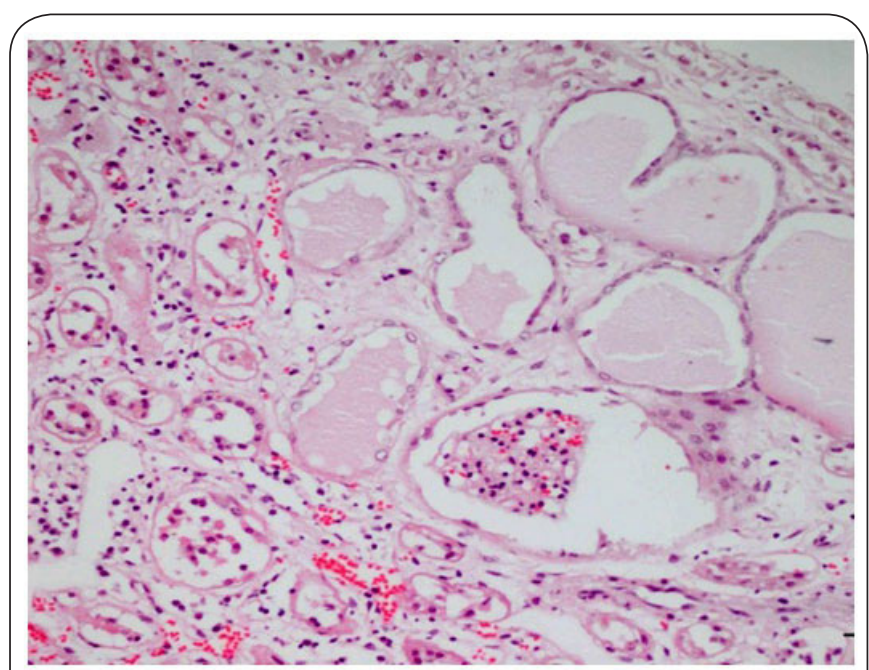

Figure 5. Kidney, (Case II), exhibiting the variable sized cystic spaces of the degenerated tubules. HE Bar $=100 \mu \mathrm{m}$.

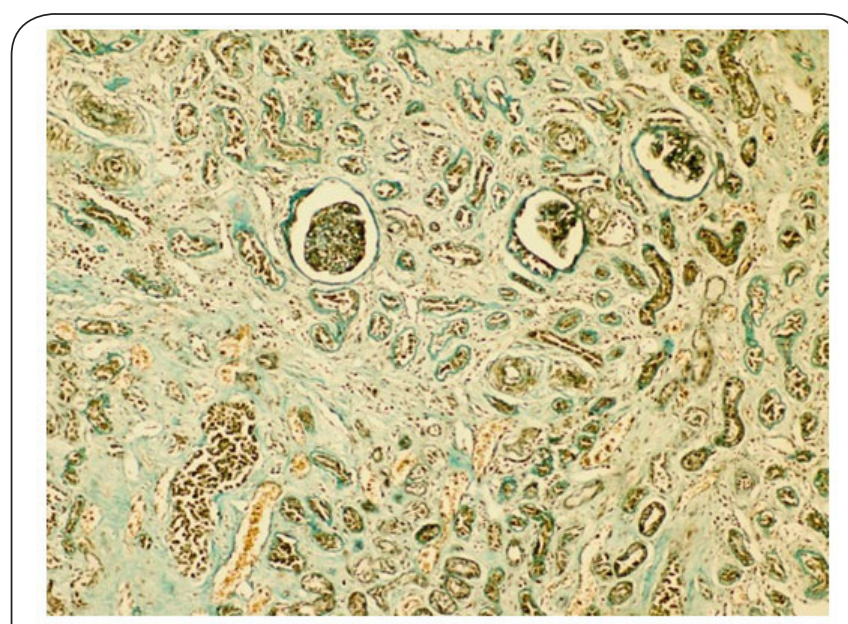

Figure 6. Kidney, (Case II), Green fibrous interstitium simulating very close to indistinct bony matrix. Masson's Trichome Bar $=100 \mu \mathrm{m}$. 
given in the feed (special ration) during dry and pregnancy period to ruminants particularly cattle and buffalo. The excess haemoconcentration of sodium and phosphorus following additional salt feeding with high concentrates ration could be linked to the inciting factor for renal fibrosis and nephrolithiasis to this case. High dietary salt feeding is essentially connected to cause renal fibrosis besides left ventricular hypertrophy and intramyocardial fibrosis [18] in rats. Earlier studies indicated excess sodium $\left(\mathrm{Na}^{+}\right)$in blood, inducing vasoconstriction mechanism [19] and facilitating profibrogenic effect of vasoactive hormones like Angiotensin II and Endothelins to stimulate the production of Transforming growth factor $\beta 1$ (TGF $\beta 1$ ) by tubular epithelial cells in rats, thus enables tubulointerstitial fibrosis and glomeruloscelorosis by stimulating deposition of matrix protein [20]. The special Masson's Trichome staining also elaborated dense collagenous interstitial matrix as similar to bony matrix, presumed to be impaired matrix turnover possibly because of up-regulated expression of tissue inhibitor of matrix metalloproteinase-1 (TIMP-1) by excess Angiotensin II [21], which eventually prevents extracellular matrix degradation. The excess phosphorus in the usual concentrate feeds is believed to act as potential factor for urolithiasis in ruminants, hypothesized to cause additional effect on tissue inhibition of metalloproteinase aggravating renal fibrosis and enhancing the inflammatory conditions in the given case. Unfortunately, the present case also lack blood chemistry and other suitable studies to buttress the condition. The round appearance of heart in this case can possibly be due to the increase in systolic blood pressure (SBP), owing to high blood concentration of sodium $\left(\mathrm{Na}^{+}\right)$causing over exertion to right ventricular muscle to work. Histologically, the matrix behind the formation of kidney stones was not appreciated in any of the case. However, we believe, the cellular infiltration in interstitium and around many tubules may have contained smaller specks of stone, which in turn initially invoked an inflammatory response.

Looking at certain scarce aspects like composition of renal liths, blood-biochemical estimation, infection loads in the two given cases, our concern in future is to report some major points in addition to pathologic descriptions that can be completely transposed in to other areas of veterinary medicine as well as in human medicine.

\section{Conclusion}

We believe that the elucidation of renal pathology due to renal-lithiasis induced fibrosis in the present study would act as a good start to carry out further research in the direction of renal fibrosis especially in animals and may further develop an alternative or therapeutic line to deal with such commonly encountered precarious situations in veterinary medicine, which needs to be pursued.

List of abbreviations

H\&E: Haematoxylin and Eosin
PCT: Proximal convoluted tubules

NSAID: Non steroidal anti-inflammatory drugs

$\mathrm{Ca}^{2+}$ : Cytosolic calcium

DCT: Distal convoluted tubule

COX: Cyclo-oxygenase enzymes

$\mathrm{Na}^{+}$: Sodium

TGF $\beta 1$ : Transforming growth factor $\beta 1$

TIMP-1: Tissue inhibitor of matrix metalloproteinase-1

SBP: Systolic blood pressure

\section{Competing interests}

The authors declare that they have no competing interests.

Authors' contributions

\begin{tabular}{|l|c|c|c|c|}
\hline Authors' contributions & SD & HSB & NDS & RSB \\
\hline Research concept and design & $\checkmark$ & -- & -- & -- \\
\hline Collection and/or assembly of data & $\checkmark$ & -- & $\checkmark$ & -- \\
\hline Data analysis and interpretation & $\checkmark$ & $\checkmark$ & -- & -- \\
\hline Writing the article & $\checkmark$ & $\checkmark$ & -- & -- \\
\hline Critical revision of the article & -- & -- & -- & $\checkmark$ \\
\hline Final approval of article & $\checkmark$ & $\checkmark$ & $\checkmark$ & $\checkmark$ \\
\hline
\end{tabular}

Acknowledgement

The authors are thankful to Dean, College of Veterinary Science, GADVASU, Ludhiana, India, for providing necessary facility to articulate this case article for widespread cognizance.

Publication history

EIC: Olivier A. E. Sparagano, Coventry University, UK.

Received: 08-Feb-2015 Final Revised: 25-Mar-2015

Accepted: 23-Apr-2015 Published: 01-May-2015

\section{References}

1. Petersson KH, Warner RG, Kallfelz FA and Crosetti CF. Influence of magnesium, water, and sodium chloride on urolithiasis in veal calves. J Dairy Sci. 1988; 71:3369-77 | Article | PubMed

2. Jubb KVF, Kennedy PC and Palmer N. Pathology of Domestic Animals. fourth ed. Academic Press Inc. 1993; 523-531.

3. Huang $\mathrm{KH}$, Gao JB, Wang $\mathrm{XL}$ and $\mathrm{Yu} \mathrm{ZH}$. Investigation of bovine and ovine uroliths induced by cotton seed meal feeding. Chinese J Vet Med. 1993; 19:11-12.

4. Wang JY, Sun WD and Wang XL. Comparison of effect of high intake of magnesium with high intake of phosphorus and potassium on urolithiasis in goats fed with cottonseed meal diet. Res Vet Sci. 2009; 87:79-84. | Article | PubMed

5. Hooper RN and Taylor TS. Urinary surgery. Vet Clin North Am Food Anim Pract. 1995; 11:95-121. | Article | PubMed

6. Larson BL. Identifying, treating, and preventing of bovine urolithiasis. Vet Med-US. 1996; 91:366-377.

7. Maes DG, Vrielinck J, Millet S, Janssens GP and Deprez P. Urolithiasis in finishing pigs. Vet J. 2004; 168:317-22. | Article | PubMed

8. Luna LG. Manual of histologic staining methods of Armed Forces Institute of Pathology. $3^{\text {rd }}$ Edn. McGraw Hill Book Co., New York. 1968.

9. Carvalho FS, Bagetti Filho HJ, Henry RW and Pereira-Sampaio MA. The bovine kidney as an experimental model in urology: external gross anatomy. Cells Tissues Organs. 2009; 190:53-8. | Article | PubMed

10. Hammond L, Ketchum J and Schwartz BF. A new approach to urology training: a laboratory model for percutaneous nephrolithotomy. J Urol. 2004; 172:1950-2. | Article | PubMed

11. Earp PP. Percutaneous renal surgery--new model for learning and training. Int Braz J Urol. 2003; 29:151-4. | Article | PubMed

12. Whelton $A$ and Hamilton CW. Nonsteroidal anti-inflammatory drugs: 
Deshmukh et al. Veterinary Medicine and Animal Sciences 2015,

effects on kidney function. J Clin Pharmacol. 1991; 31:588-98. | Article I PubMed

13. Ejaz P, Bhojani K and Joshi VR. NSAIDs and kidney. J Assoc Physicians India. 2004; 52:632-40. I PubMed

14. Barac-Nieto M, Constantinescu A, Pina-Benabou MH and Rozental R. Hypoxic rise in cytosolic calcium and renal proximal tubule injury mediated by a nickel-sensitive pathway. Exp Biol Med (Maywood). 2004; 229:1162-8. | Article | PubMed

15. Gobe GC and Johnson DW. Distal tubular epithelial cells of the kidney: Potential support for proximal tubular cell survival after renal injury. Int J Biochem Cell Biol. 2007; 39:1551-61. | Article | PubMed

16. Zeisberg M, Maeshima Y, Mosterman B and Kalluri R. Renal fibrosis. Extracellular matrix microenvironment regulates migratory behavior of activated tubular epithelial cells. Am J Pathol. 2002; 160:2001-8. | Article | PubMed Abstract | PubMed Full Text

17. Higuchi K, Umegaki E, Watanabe T, Yoda Y, Morita E, Murano M, Tokioka $\mathrm{S}$ and Arakawa T. Present status and strategy of NSAIDs-induced small bowel injury. J Gastroenterol. 2009; 44:879-88. | Article | PubMed

18. Yu HC, Burrell LM, Black MJ, Wu LL, Dilley RJ, Cooper ME and Johnston $\mathrm{Cl}$. Salt induces myocardial and renal fibrosis in normotensive and hypertensive rats. Circulation. 1998; 98:2621-8. | Article | PubMed

19. Salomone S, Dessy C, Morel N and Godfraind T. Inhibition by bosentan, an endothelin antagonist, of the hypersensitivity to $\mathrm{Ca} 2+$ channel activator evoked by salt-loading in basilar artery of stroke-prone spontaneously hypertensive rats. Life Sci. 1996; 59:PL247-53. | Article | PubMed

20. Burns KD. Interleukin-1beta as a mediator of tubulointerstitial fibrosis. Kidney Int. 2002; 62:346-7. | Article | PubMed

21. Bolbrinker J, Markovic S, Wehland M, Melenhorst WB, van Goor H and Kreutz R. Expression and response to angiotensin-converting enzyme inhibition of matrix metalloproteinases $\mathbf{2}$ and $\mathbf{9}$ in renal glomerular damage in young transgenic rats with renin-dependent hypertension. $J$ Pharmacol Exp Ther. 2006; 316:8-16. | Article | PubMed

\section{Citation:}

Deshmukh S, Banga HS, Singh ND and Brar RS.

Renal pathology associated with kidney stones in two buffaloes. Vet Med Anim Sci. 2015; 3:1.

http://dx.doi.org/10.7243/2054-3425-3-1 